\title{
Early learning and adaptive behaviour in toddlers with Down syndrome: Evidence for an emerging behavioural phenotype?
}

\author{
Deborah J. Fidler', Susan Hepburn ${ }^{2}$ and Sally Rogers ${ }^{3}$ \\ 'Human Development and Family Studies, Colorado State University \\ ${ }^{2}$ Department of Psychiatry, University of Colorado Health Science Center \\ ${ }^{3}$ M.I.N.D. Institute, Department of Psychiatry, University of California, Davis
}

\begin{abstract}
Background: Though the Down syndrome behavioural phenotype has been described as involving relative strengths in visuo-spatial processing and sociability, and relative weaknesses in verbal skills and motor planning, the early emergence of this phenotypic pattern of strengths and weaknesses has not yet been fully explored. Method: In this study, we compared the performance of eighteen 2 to 3 -year-olds with Down syndrome to an MA-matched comparison group of nineteen 2 to 3-year-olds with mixed developmental disabilities, and an MA-matched comparison group of 24 children with typical development on two developmental measures: the Mullen Scales of Early Learning and the Vineland Adaptive Behaviour Scales. Results: While the specificity of the Down syndrome profile was (for the most part) not yet evident, results showed that toddlers with Down syndrome in this study did show emerging areas of relative strength and weakness similar to that which has been described in older children and young adults with Down syndrome. This pattern included relatively stronger social skills, weaker expressive language, and poor motor coordination. When this pattern of strengths and weaknesses was compared to the developmental profiles of the two comparison groups, socialisation strengths differentiated the Down syndrome group from the mixed developmental disabilities group.
\end{abstract}

Keywords: Down syndrome, early development, behavioural phenotype

There is a new wealth of evidence suggesting that certain genetic disorders are associated with specific behavioural profiles, or 'behavioural phenotypes' (Dykens, 1995). Behavioural phenotypes in genetic syndromes are defined probabilistically. Thus, groups with a certain syndrome may be more likely to show one or more characteristic behaviours than other person with developmental disabilities, but not every child with a specific syndrome necessarily shows any etiology-specific behaviour (Dykens, 1995; Hodapp, 1997). This connection between genetic condition and behavioural profile has the potential to revolutionise interventions for individuals with developmental disabilities (Fidler, Hodapp \& Dykens, 2002; Fidler, Lawson \& Hodapp, 2003; Hodapp \& Fidler, 1999).

In comparison with other genetic syndromes, a relatively large amount of research attention has been devoted to describing outcomes associated with Down syndrome (Dykens, Hodapp \& Finucane, 2000). Down syndrome is the most common genetic (chromosomal) disorder, occurring in from 1 in 700 to 1 in 1000 live births (Steele, 1996;
Stoll, Alembik, Dott \& Roth, 1990; Hassold and Jacobs, 1984). In 95\% of cases, Down syndrome is caused by an extra chromosome 21.

Much of the focus of research on cognition in Down syndrome has been placed on deficits in verbal processing (Byrne, Buckley, MacDonald \& Bird, 1995; Hesketh \& Chapman, 1998; Laws, 1998). In addition, studies have found relative strengths in visuo-spatial processing in this population, and many individuals with Down syndrome have a profile of stronger visuo-spatial than verbal processing skills (Jarrold, Baddeley \& Hewes, 1999; Klein \& Mervis, 1999; Wang \& Bellugi, 1994).

Many individuals with Down syndrome have severe language delays (Sigman \& Ruskin, 1999). Part of the Down syndrome language phenotype includes a discrepancy between expressive and receptive language capabilities, including large deficits in vocabulary size relative to mental age (Miller, 1992). Children with Down syndrome also show particular deficits in the development of gram- 
mar, and many individuals with Down syndrome do not progress beyond the early stages of morphological and syntactic development (Fowler, 1990). Miller and Leddy (1999) reported that the majority of children with Down syndrome experience a prolonged period of unintelligible speech, often until age 5 or 6 .

Despite their language deficits, many children with Down syndrome show strengths in social functioning (Gibbs \& Thorpe, 1983; Rodgers, 1987; Wishart \& Johnston, 1990). Children with Down syndrome may also use relative strengths in social skills to compensate for other weaker domains of functioning. In one study, young children with Down syndrome not only showed more looks to the experimenter during a difficult task, but they also showed more off-task 'party pieces' that engaged the experimenter socially (Pitcairn \& Wishart, 1994). Individuals with Down syndrome may also show relative competence in forming relationships with others (Freeman \& Kasari 2002).

Another aspect of the Down syndrome behavioural phenotype involves difficulties with motor skills and motor planning (Jobling, 1999; Jobling, 1998; Mon-Williams et al., 2001). Jobling (1998) found that children with Down syndrome show delays in the development of aspects of gross motor and fine motor skills, though aspects of motor development were found to be CA-appropriate. Similar relative weaknesses have been demonstrated in motor planning, or praxis (Mon-Williams, et al., 2001).

While there is a growing body of knowledge regarding the Down syndrome behavioural phenotype, much of what is known is based on research involving older children, adolescents, and adults with Down syndrome (Haxby, 1989; Jobling, 1998; Varnhagen, Das \& Varnhagen, 1987; Vicari, Carlesimo \& Caltagirone, 1995; Wang \& Bellugi, 1994). By studying only older children and adults, researchers may have a false impression that phenotypic outcomes are static in nature, and that areas of relative strength and weakness are present from the earliest stages of development. Yet, Nadel (1995) notes that most measures of brain development and cognitive functioning are in the normal range during the first few months of infancy in Down syndrome. If this is so, then the emergence of the Down syndrome phenotype during early development may be of great importance to early interventionists. What precipitates the evolution of the phenotypic profile associated with Down syndrome? And, is there a way to strengthen development of areas that are expected to develop more slowly, and thus prevent relative developmental weaknesses downstream?

In addition, most behavioural phenotype research focuses on one dimension of development in isolation (i.e. working memory, praxis, joint attention). While detailed descriptions of a specific domain of functioning are important, it may also be informative to explore how many areas develop together - for example, to show whether cross-domain areas of relative strength and weakness become more pronounced over time. Such findings may inform interventions that take into account the whole child, not simply one aspect of the child that may be of particular interest.
Two questions will be addressed in this study. First, are developmental profiles in toddlers with Down syndrome specific to Down syndrome? This question will be addressed with between-group analyses. And second, are distinct areas of strength and weakness in functioning already present in early childhood? This question will be addressed using within-Down syndrome analyses. In order to answer these questions, we will analyse the performance of 2 to 3 -yearolds with Down syndrome on the Mullen Scales of Early Learning and the Vineland Adaptive Behaviour Scales. We compare the performance of 2-3 year-olds with Down syndrome with that of a MA-matched comparison group of 2 to 3-year-olds with developmental disabilities, and an MAmatched group of typically developing 1 to 2 -year-olds.

\section{Materials and Methods}

\section{Procedures}

This study was part of a larger longitudinal study of the developing phenotypes of autism, fragile X syndrome, and Down syndrome. Participants were recruited through the JFK Partners University Affiliated Program and parent support groups in the Denver Metropolitan Area (e.g., Mile High Down Syndrome Association, Fragile X Foundation). The entire study was carried out under Institutional Review Board approval. Consent forms were reviewed with each family and all questions were answered before consent was obtained and before any measures were gathered. All examiners were completely blind to the questions being asked in this study and limited knowledge regarding the Down syndrome behavioural phenotype (their expertise was in children with autism).

The Mullen Scales were administered in a laboratory visit in a standardised fashion. All examiners were masters or doctoral level clinicians with several years of clinical experience working with young children with developmental disabilities. Mothers were interviewed for the Vineland Scales, generally during a home visit.

\section{Measures}

Experimenters administered a battery of developmental tests including:

1. Mullen Scales of Early Learning (MSEL; Mullen, 1995). The MSEL is a standardised developmental test for children ages 3 to 60 months consisting of five subscales: gross motor, fine motor, visual reception, expressive language, and receptive language. The MSEL allows for separate standard verbal and nonverbal summary scores to be constructed and demonstrates strong concurrent validity with other well-known developmental tests of motor, language, and cognitive development (Mullen, 1995). Internal consistency of the five subdomains ranges from .75 to .83 , evidence that the subscales measure distinct abilities. High correlations have been found between the MSEL and the Bayley Scales of Infant Development, the Preschool Language Assessment, and the Peabody Fine Motor Scale. 
The MSEL was administered to all subjects according to standard instructions by raters with advanced degrees, trained in assessing young children with autism and other developmental disorders. Reinforcers for all subjects in all groups were used at times to reward cooperation and attention.

The Receptive Language Scale provides an assessment of a child's ability to decode verbal input. The majority of questions require a nonverbal response (such as pointing), with the exception of one higher-level item, which requires a child to answer questions in order to ascertain their general knowledge skills. Tasks on this scale assess a child's understanding of verbal instructions, auditory-spatial and auditory-quantitative concepts, memory for commands and general concepts. Difficulty with items on this scale is hypothesised to be related to impairments deriving linguistic meaning from spoken language (Mullen, 1995).

The Expressive Language Scale assesses a child's spontaneous language, specific vocal or verbal responses to questions, and high-level concept formation (Mullen, 1995). The expressive language tasks are all considered intrasensory, requiring the child to respond to an auditory prompt or question. Expression is not completely independent of comprehension, and auditory discrimination and vocal motor skills are necessary for responses on this scale. Difficulties on this scale may be attributable to any of the following: difficulties with syntax, dyspraxia, or auditory memory (Mullen, 1995).

The Visual Reception Scale focuses on visual perceptual ability with minimal response requirements. Children are presented with visual information in various forms and patterns, involving oculomotor and visual motor operations (e.g. localising on a target, visual tracking, scanning multiple points on a surface). Tasks assess visual discrimination and visual memory. Vocalisations are not required for responses but some instructions are given verbally, accompanied by gesture and pantomimed instruction.

The Gross Motor Scale tasks assess skills including head control, sitting, pulling to stand, rotating from sitting to hands/knees, and walking. The subtest is designed to measure the organised progression of cephalocaudal and proximodistal motor development.

The Fine Motor Scale involves bilateral and unilateral manipulation. Bilateral items include turning pages in a book, unscrewing/screwing a nut and bolt, stringing beads, folding, and cutting. Unilateral items include stacking blocks, putting pennies in horizontal or vertical slots, imitating block models, and drawing or writing. These tasks involve both motor planning, or praxis skills, and motor control.

2. Vineland Scales of Adaptive Behaviour, Interview Edition. The Vineland (Sparrow, Balla \& Cicchetti, 1984) is a 291item standardised parent interview for children ages birth to 18 years. The Vineland is designed to assess adaptive behaviour across four domains: socialisation, communication, daily living, and motor skills. The Vineland provides norm-referenced information based on the performance of representative national standardisation samples of 4,800 typically and atypically developing children.

The Socialisation Domain assesses functioning in interpersonal relationships, play and leisure time, and coping skills. For toddlers, interpersonal relationship items involve dimensions like "laughs or smiles appropriately in response to positive statements", play and leisure time items for toddlers involve dimensions like "participates in at least one game or activity with others", and coping skills involve items like "says 'please' when asking for something". For the daily living skills domain, toddler personal daily living skills items include behaviours like "feeds self with spoon without spilling", the community living skills items for toddlers involve dimensions like "demonstrates understanding of the function of money", and the domestic daily living skills subdomain involves items like "puts possessions away when asked". The communication domain involves expressive language items like "says at least 50 words", and receptive language items like "points accurately to all body parts when asked". The motor domain involves toddler gross motor items like "pedals tricycle or other threewheeled vehicle for at least six feet", and fine motor items like "screws and unscrews lid of jar."

The Vineland was administered in order to understand how the children actually used their skills in representative, generalised, real life settings, outside of the structure and scaffolding provided in the laboratory situation.

3. Demographics Questionnaire. Parents were asked about information regarding parents' age, SES (Hollingshead, 1975), education level, and ethnicity.

Participants. Participants were eighteen 2 to 3 -year-old children with Down syndrome, nineteen 2 to 3 -year-old children with mixed etiologies of developmental delays, and $24 \mathrm{MA}$-matched typically developing infants and toddlers. There were no differences between clinical groups on gender or child chronological age, and children in both disability groups averaged a CA of around 33 months (See Table 1 for all demographic and developmental information). Children in the typically developing group had an average CA of 19.5 months $(\mathrm{SD}=4.98)$. Children in all groups were also equated on MSEL mental age as well, averaging an overall MA 21-23 months on the Mullen scales. Children in all groups all had normal vision and hearing or vision corrected to within the normal range, had unimpaired hand use, and were mobile.

All children with Down syndrome had a genetic diagnosis of trisomy 21 . Within the developmental disabilities comparison group, thirteen of the children had other genetic abnormalities (fragile X syndrome without autism, Velocardiofacial syndrome, Cochayne syndrome, partial deletion on chromosome 18, abnormalities on chromosome 15) and six had developmental delays of unknown etiology. There were no differences in prevalence of premature births (born before 36 weeks gestation) between the Down syndrome and other two groups, $X^{2}(2, \mathrm{n}=55)=1.90$, ns. In addition, there were no between-disability group differ- 
Table I. Demographic and developmental information

\begin{tabular}{|c|c|c|c|c|}
\hline & Down syndrome & $\begin{array}{l}\text { Developmental } \\
\text { disabilities }\end{array}$ & Typically developing & $F$ or $X^{2}$ \\
\hline $\begin{array}{l}\text { Child CA } M \text { in months } \\
\text { (sd, min-max) }\end{array}$ & $33.94(7.75 ; 24-47)$ & $34.47(7.64 ; 23-50)$ & $19.58(4.98 ; 12-35)$ & $\begin{array}{l}34.19 * * \\
D S, D D>\text { typ }\end{array}$ \\
\hline $\begin{array}{l}\text { Child Gender } \\
\text { Male:Female }\end{array}$ & $11: 7$ & $15: 4$ & $10: 14$ & $\begin{array}{l}7.29 * * \\
\text { DS, DD <typ }\end{array}$ \\
\hline Premature birth \% (n) & $13.3 \%(2)$ & $17.6 \%(3)$ & $4.3 \%(I)$ & 1.90 \\
\hline $\begin{array}{l}\text { Overall Child MSEL MSEL MA in } \\
\text { months (sd; min-max) }\end{array}$ & $21.10(6.10 ; 14-33)$ & $20.4 \mid(5.08 ;|4-3|)$ & $23.44(6.28 ;|4-4|)$ & 1.60 \\
\hline Child Ethnicity & $\begin{array}{l}\text { 88.8\% Caucasian } \\
5.6 \% \text { Latino } \\
5.6 \% \text { biracial }\end{array}$ & 100\% Caucasian & $\begin{array}{l}\text { 87.0\% Caucasian } \\
4.3 \% \text { Latino } \\
8.7 \% \text { Biracial }\end{array}$ & 2.64 \\
\hline $\begin{array}{l}\text { Father Age in years } M \\
\text { (s.d.; min-max) }\end{array}$ & $39.53(5.37 ; 29-5 I)$ & $37.50(6.34 ; 30-57)$ & $32.57(5.33 ; 24-34)$ & $\begin{array}{l}7.29 * * \\
D S, D D>\text { typ }\end{array}$ \\
\hline $\begin{array}{l}\text { Mother Age in years } M \\
\text { (s.d.; min-max) }\end{array}$ & $37.60(4.43 ; 30-44)$ & $34.88(4.55 ; 28-46)$ & 31.31 (5.64; 22-44) & $\begin{array}{l}7.27 * * \\
D S, D D>\text { typ }\end{array}$ \\
\hline SES (s.d.; min-max) & $56.49(7.00 ; 40-66)$ & $50.37(11.96 ; 15-66)$ & $47.97(14.43 ; 22-66)$ & 2.29 \\
\hline
\end{tabular}

ences in the amount of early intervention services received for speech therapy, $X^{2}(1, n=33)=1.28$, ns, occupational therapy, $X^{2}(1, \mathrm{n}=33)=1.13$, ns; specialised preschool attendance, $X^{2}(1, \mathrm{n}=33)=.97$, ns; public special ed preschool attendance, $X^{2}(1, \mathrm{n}=33)=1.51$, ns; structured home programs, $X^{2}(1, \mathrm{n}=33)=0.002$, ns; mainstream preschool attendance, $X^{2}(1, n=33)=.51$, ns.

No between-group differences were observed on parent age and SES, though parents of typically developing children were younger than parents in the disability groups (see Table 1 for parent demographic information). No relationship was found between child MSEL MA and family SES in the Down syndrome group, $r(16)=-.13$, ns; the developmental disabilities comparison group $r(17)=.31$, ns; and in the typical controls, $r(22)=-.01$, ns. The lack of relationship between SES and child functioning in the clinical groups most likely reflects the strong biological origins of the children's disorders, though a modest association was observed in the developmental disabilities comparison group, as might be expected. SES is more often related to child developmental variables in children with milder intellectual delays and those from a more impoverished background. Similarly, the lack of relationships between SES and the typical children's functioning most likely reflects the narrow range of SES and the middle class status of this group.

\section{Results}

Mullen Scales. A 3 (Down syndrome versus comparison group versus typically developing children) by 5 ( $5 \mathrm{MSEL}$ domains) MANOVA was performed in order to assess specificity of MSEL profiles across the three groups. Using Wilks' criterion, the profiles, seen in Figure 1, deviated significantly from parallelism, $F(4,55)=8.28, p<.0001$, observed power $=.99$ (see Table 2 for means and standard deviations). Post-hoc one-way ANOVA analyses suggest that no significant differences were found between the Down syndrome and the other two groups, and that the source of significant difference among the three groups was expressive language differences between the typical and developmental disabilities groups, $F(2,56)=6.74, p<.005$ $(\mathrm{DD}<$ typ).

In addition to exploring whether the Down syndrome outcomes were specific to that group, a second analysis was conducted to explore within-Down syndrome variation in MSEL performance. A one-way repeated measures ANOVA showed that children with Down syndrome did indeed show distinct areas of strength and weakness within their profile, $F(4,14)=3.44, p<.05$, observed power $=.71$. On average, children with Down syndrome showed stronger performances on the visual reception (age equivalent $M=21.22$ months) and receptive language (age equivalent $M=22.11$ months) domains of the MSEL. Their performances on the MSEL gross motor (age equivalent $M=18.22$ months) and the expressive language subtests (age equivalent $M=19.33$ months) were relatively weaker. Post-hoc analyses showed 
Table 2. MSEL domain age-equivalent scores

\begin{tabular}{|l|l|l|l|l|}
\hline & Down syndrome & $\begin{array}{l}\text { Developmental } \\
\text { disabilities }\end{array}$ & Typical & $F(2,58)$ \\
\hline Gross Motor M (s.d.) & $18.22(7.59)$ & $20.26(4.54)$ & $18.83(5.33)$ & .59 \\
\hline Visual Reception M (s.d.) & $21.22(7.45)$ & $22.63(6.49)$ & $22.50(7.16)$ & .23 \\
\hline Fine Motor M (s.d.) & $20.83(5.8 \mathrm{I})$ & $20.68(4.57)$ & $22.63(5.6 \mathrm{I})$ & .88 \\
\hline Receptive Language M (s.d.) & $22.11(7.00)$ & $22.58(8.24)$ & $24.62(7.11)$ & .69 \\
\hline Expressive Language M (s.d.) & $19.33(6.49)$ & $15.47(6.8 \mathrm{I})$ & $23.7 \mathrm{I}(8.27)$ & $6.74 * *$ \\
& & & & Typ>DD \\
\hline
\end{tabular}

$* \mathrm{p}<.05, * * \mathrm{p}<.01$

Table 3. Vineland domain age-equivalent scores

\begin{tabular}{|l|l|l|l|l|}
\hline & Down syndrome & $\begin{array}{l}\text { Developmental } \\
\text { disabilities }\end{array}$ & Typical & F (2, 58) \\
\hline Communication M (s.d.) & $18.17(4.6 \mathrm{I})$ & $16.44(2.55)$ & $21.6 \mathrm{I}(7.29)$ & $\begin{array}{l}4.89 * * \\
\text { Typ }>\text { DD }\end{array}$ \\
\hline Daily Living Skills M (s.d.) & $18.94(4.79)$ & $18.17(3.01)$ & $20.61(4.93)$ & I.67 \\
\hline Socialisation M (s.d.) & $20.17(4.08)$ & $15.22(4.15)$ & $\begin{array}{l}8.12 * * \\
\text { DS, typ }>\text { DD }\end{array}$ \\
\hline Motor Skills M (s.d.) & $17.83(4.68)$ & $20.89(5.06)$ & $20.39(5.07)$ & 2.02 \\
\hline
\end{tabular}

* $\mathrm{p}<.05,{ }^{* *} \mathrm{p}<.01$

that children in this sample showed a significant dissociation between receptive and expressive language, $t(17)=$ $3.17, p<.01$; and between receptive language and gross motor skills, $t(17)=2.48, p<.05$.

Vineland Adaptive Behaviour Scales. A 3 (Down syndrome versus comparison group versus typical) by 4 (Vineland domains) MANOVA was performed in order to assess specificity of adaptive behaviour outcomes across the three groups. Using Wilks' criterion, the profiles deviated significantly from parallelism, $F(8,196)=8.00, p<.0001$, observed power $=.99$. Post-hoc one-way ANOVAs show that the source of significant difference among the three groups lay in socialisation differences, $F(2,56)=8.12, p$ $<.001$ (DS, typ $>$ DD) and communication differences, $F$ $(2,56)=4.89, p<.01$ (typ $>$ DD). Thus, the strength in social relationships often associated with Down syndrome was demonstrated.

Further analyses were conducted to assess the within-Down syndrome performance profile on the Vineland. One-way Repeated Measures ANOVA showed that children with Down syndrome again showed distinct areas of strength and weakness in functioning, this time in adaptive behaviour, $F(3,19)=3.89, p<.05$, observed power $=.79$. Posthoc analyses show that children with Down syndrome had significantly stronger socialisation than communication scores $t(17)=4.42, p<.0001$, and stronger socialisation than motor skills scores, $t(17)=2.87, p<.01$.
One area of particular relative strength in socialisation involved Play and Leisure Time items. Age equivalent scores for the Down syndrome group in this study on Play and Leisure Time socialisation sub-domain averaged 23.8 months. In contrast, the interpersonal relationship area of the Vineland socialisation domain showed average age equivalent scores of 18.7 months. A paired-sample t-test shows significant within subject differences on these two aspects of socialisation, $t(17)=3.38, p<.005$.

Similarly, within the Vineland communication domain, children in the Down syndrome group showed dissociations between receptive and expressive language, $t(17)=5.15, p$ $<.0001$. As observed with the MSEL, these children had significantly higher receptive language communication subdomain scores $(M=26.1$ months $)$ than expressive language communication sub-domain scores $(M=16.1$ months $)$. It should be noted that some discrepancy between parent report and child battery scores were observed on communication domains. Though these discrepancies were found, parent report and child battery measures were highly correlated for the Down syndrome group, for receptive language, $r(16)=.83, p<.0001$, and expressive language, $r$ $(16)=.82, p<.0001 ;$ and collapsed across all groups for receptive language, $r(59)=.70, p<.0001$, and expressive language, $r(59)=.85, p<.0001$. 


\section{Discussion}

Previous studies have reported a specific behavioural phenotype, or distinct areas of relative strength and weakness in cognition, language, social functioning, and motor skills, associated with the diagnosis of Down syndrome. However, these findings have focused primarily on older children and young adults. This study was designed to examine the origins of that phenotype by examining the developmental and behavioural profiles of toddlers with Down syndrome. Is the specific phenotype present at the earliest points in development that it can be measured, as intentional communication is emerging and thus represents a 'starting state'? Or does it develop more slowly across the preschool years, as various developmental skills become more practised and as they acquire their own experiential history?

The performance of young children with Down syndrome in this study was compared to the performance of a comparison group of children with other developmental disabilities and a group of typically developing children, all matched for developmental levels. Children's performance was assessed on both laboratory administered measures and on parent reports of naturally occurring behaviours in real life situations.

In terms of specificity, the children with Down syndrome in this study showed significantly higher Vineland Socialisation scores than the developmental disabilities comparison group. No other areas of functioning distinguished the Down syndrome group from the other two groups. These findings suggest that while some specificity was observed in socialisation, for the most part the specificity of the Down syndrome profile in toddlerhood was not established in this study.

However, when the profile within Down syndrome was examined, children with Down syndrome in this study did show relative strengths on the laboratory based developmental measure in the areas of visual processing and receptive language, and relative weaknesses in gross motor skills and expressive language. In terms of parent reported skills in adaptive behaviour in real-life situations, the children with Down syndrome in this study showed relative strengths in socialisation and relative weakness in communication and motor skills. Thus, there is evidence that the behavioural phenotype associated with Down syndrome is emerging by the age of three, with between-group differences in sociability, and within-group patterns of relative strengths and weaknesses that foreshadow the phenotype described in studies of older persons.

This paper is part of a larger movement toward viewing behavioural phenotypes from a developmental perspective. Recently, researchers have begun to call for a reframing of phenotype research to include the neglected aspect of development. As an example, Karmiloff-Smith (1997) has argued for the importance of studying the development of the language in Williams syndrome - that many young children with Williams syndrome do not show the pronounced relative strength in language, but these phenotypic outcomes emerge and become pronounced during development. Studies to date that have taken a developmental approach to behavioural phenotypes have similarly found that areas of strength develop at a faster rate than areas of weakness over time in fragile $\mathrm{X}$ syndrome and Down syndrome (Hodapp, Leckman, Dykens, Sparrow, Zelinsky \& Ort, 1992; Miller, 1992).

It is notable that two of the dissociations observed within the individuals with Down syndrome were significant, but also relatively small at these early developmental ages. Even in the significant difference between expressive and receptive language, differences averaged only 2.5 months. In other studies with older children with Down syndrome, dissociations between domains of functioning can be much larger. This does not minimise the rapid changes that take place over several months in early development. But the relatively small dissociation is also notable for intervention purposes - because areas of strength and weakness are less pronounced early on, it may be possible to reduce these dissociations and set areas of potential weakness on more optimal pathways. That small dissociations early in development can result in increasingly larger differences over time is consistent with dynamic systems theory in that small starting state differences can evolve considerably as development becomes increasingly complex and differentiated.

Though several features of the Down syndrome behavioural phenotype were observed in this 2 to 3 -year-old sample, other dissociations that are observed in later development did not seem to be present at this age. We did not observe differences in performance on visual processing versus receptive language tasks. The expected dissociation between visual and verbal processing in Down syndrome, according to our results, was not yet present. This, too, may have important implications for intervention. Alternatively, the lack of observed dissociation may also result from administrative aspects of the MSEL receptive language scale, which include modeling, gesturing, and parent report.

Several limitations to this study must be noted. First, our measure of adaptive behaviour, the Vineland Adaptive Behaviour Scales, is a parent report measure, based on generally observed behaviour rather than explicitly elicited and scaffolded behaviour, and this may account for discrepancies in age-equivalent scores across the two measures. Second, these measures reflect general functioning in several broad areas, and future studies should explore patterns of performance within these broad categories. Third, these findings are based on relatively small sample sizes and are only suggestive, not conclusive. Findings need to be replicated with a larger sample size.

This study contributes to the larger movement toward examining behavioural phenotypes in children with genetic syndromes. In describing the particular behavioural outcomes associated with genetic syndromes, we gain information needed to develop targeted educational and intervention programs for specific learning profiles. By understanding the early developmental trajectory of a particular set of out- 
comes, we may be able to develop interventions that are time-sensitive, and that prevent or offset potential future delays. These findings have stimulated several questions for future studies. Two of the most pressing involve the stability of individual profiles of strengths and weaknesses over time, and the determination of environmental and biological events that affect the development and stability of the profile of abilities.

\section{Correspondence}

Deborah J. Fidler, Ph.D. • 102 Gifford Building, 502 West Lake Street, Colorado State University, Fort Collins, CO, 80523•E-mail: Deborah.Fidler@colostate.edu.

\section{Acknowledgments}

Dr. Rogers and Dr. Hepburn are partially supported by NICHD U19 HD35468, and by NIDCD R21 05574. The intellectual support of the Developmental Psychobiology Research Group is gratefully acknowledged. This program of research is part of the Collaborative Programs of Excellence in Autism. The authors also thank Amy Philofsky, Galit Mankin, and Athena Hayes for their contributions to this project.

\section{References}

Byrne, A., Buckley, S., MacDonald, J. \& Bird, G. (1995). Investigating the literacy, language, and memory skills of children with Down's syndrome. Down's Syndrome: Research and Practice, 3, 53-58.

Dykens, E.M. (1995). Measuring Behavioral phenotypes: Provocations from the "new genetics." American Journal on Mental Retardation, 99, 522-532.

Dykens, E.M., Hodapp, R.M. \& Finucane, B.M. (2000). Genetics and Mental Retardation Syndromes: A New Look at Behavior and Interventions. Baltimore: Paul $\mathrm{H}$. Brookes Publishing.

Fidler, D.J., Hodapp, R.M. \& Dykens, E.M. (2002). Behavioral phenotypes and special education: Parent report of educational issues for children with Down syndrome, Prader-Willi syndrome, and Williams syndrome. Journal of Special Education, 36, 80-88.

Fidler, D.J., Lawson, J. \& Hodapp, R.M. (2003). What do parents want?: An analysis of education-related comments made by parents of children with different genetic mental retardation syndromes. Journal of Intellectual and Developmental Disabilities, 28, 196-204.

Fowler, A.E. (1990). Language abilities in children with Down syndrome: Evidence for a specific syntactic delay. In D. Cicchetti and M. Beeghly, (Eds.), Children with Down Syndrome: A Developmental Perspective, (pp. 302328). New York: Cambridge University Press.

Freeman, S.F.N. \& Kasari, C. (2002). Characteristics and qualities of the play dates of children with Down syndrome: Emerging or true friendships? American Journal on Mental Retardation, 107, 16-31.

Gibbs, M.V. \& Thorpe, J.G. (1983). Personality stereotype of noninstitutionalized Down Syndrome children. American Journal of Mental Deficiency, 87, 601-605.

Hassold, T.J. \& Jacobs, P.A. (1984). Trisomy in man. Annual Review of Genetics, 18, 69-97.
Haxby, J.V. (1989). Neuropsychological evaluation of adults with Down's syndrome: Patterns of selective impairment in non-demented old adults. Journal of Mental Deficiency Research, 33, 193-210.

Hesketh, L.J. \& Chapman, R.S. (1998). Verb use by individuals with Down syndrome. American Journal on Mental Retardation, 103, 288-304.

Hodapp, R.M. (1997). Direct and indirect behavioural effects of different genetic disorders of mental retardation. American Journal on Mental Retardation, 102, 67-79.

Hodapp, R.M., Leckman, J.F., Dykens, E.M., Sparrow, S.S., Zelinsky, D. \& Ort, S.I. (1992). K-ABC profiles in children with fragile X syndrome, Down syndrome, and non-specific mental retardation. American Journal on Mental Retardation, 97, 39-46.

Hodapp, R.M. \& Fidler, D. J. (1999). Special education and genetics: Connections for the $21^{\text {st }}$ century. Journal of Special Education, 22, 130-137.

Hollingshead AB. Manual for the four factor indeMof social status. Unpublished manuscript: Yale University; 1975.

Jarrold, C., Baddeley, A.D. \& Hewes, A.K. (1999). Genetically dissociated components of working memory: Evidence from Down's and Williams syndrome. Neuropsychologia, 37, 637-651.

Jobling, A. (1999). Attainment of motor proficiency in school-aged children with Down syndrome. Adapted Physical Activity Quarterly, 16, 344-361.

Jobling, A. (1998). Motor development in school-aged children with Down syndrome: A longitudinal perspective. International Journal of Disability, Development and Education, 45, 283-293.

Karmiloff-Smith, A. (1997). Crucial differences between developmental cognitive neuroscience and adult neuropsychology. Developmental Neuropsychology, 13, 513-524.

Klein, B.P. \& Mervis, C.B. (1999). Contrasting patterns of cognitive abilities of 9- and 10 - year-olds with Williams syndrome or Down syndrome. Developmental Neuropsychology, 16, 177-196.

Laws, G. (1998). The use of nonword repetition as a test of phonological memory in children with Down syndrome. Journal of Child Psychology and Psychiatry and Allied Disciplines, 39, 1119-1130.

Miller, J.F. (1992). Lexical development in young children with Down syndrome. In R. Chapman (Ed.), Processes of Language Acquisition and Language Disorders, (pp. 202216). St. Louis, Moby Press.

Miller, J. F. \& Leddy, M. (1999). Verbal fluency, speech intelligibility, and communicative effectiveness. In J.F Miller, M. Leddy \& L.A. Leavitt (Eds.), Improving the communication of people with Down syndrome, (pp. 81-91). Baltimore, MD: Paul H. Brookes

Mullen, E. (1995). Mullen Scales of Early Learning. Circle Pines: American Guidance Service, Inc.

Mon-Williams, M., Tresilian, J.R., Bell, V.E., Coppard, V.L., Jobling, A. \& Carson, R.G. (2001). The preparation of reach to grasp movements in adults with Down syndrome. Human Movement Science, 20, 587-602.

Nadel, L. (1995). Neural and cognitive development in Down syndrome. In L. Nadel \& D. Rosenthal (Eds). 
Down Syndrome: Living and Learning in the Community, (p.107-114). New York: Wiley-Liss.

Pitcairn, T.K. \& Wishart, J.G. (1994). Reactions of young children with Down's syndrome to an impossible task. British Journal of Developmental Psychology, 12, 485-489.

Rodgers, C. (1987). Maternal support for the Down's syndrome stereotype: The effect of direct experience of the condition. Journal of Mental Deficiency Research, 31, 217-278.

Sigman, M. \& Ruskin, E. (1999). Continuity and change in the social competence of children with autism, Down syndrome, and developmental delays. Monographs of the Society for Research in Child Development, 64, v-114.

Sparrow, S.S., Balla, D.A. \& Cicchetti, D.V. (1984). Vineland Adaptive Behavior Scales: Interview Edition (Survey Form). Circle Pines, MN: American Guidance Services.

Steele, J. (1996). Epidemiology: Incidence, prevalence and size of the Down's syndrome population. In B. Stratford \& P. Gunn (Eds.), New Approaches to Down Syndrome. London: Cassell.

Stoll, C., Alembik, Y., Dott, B. \& Roth, M.P. (1990). Epidemiology of Down syndrome in 118, 625 consecutive births. American Journal of Medical Genetics - Supplement, 7, 79-83.

Varnhagen, C.K., Das, J. P. \& Varnhagen, S. (1987). Auditory and visual memory span: Cognitive processing by TMR individuals with Down syndrome or other etiologies. American Journal of Mental Deficiency, 91, 398-405.

Vicari, S., Carlesimo, A. \& Caltagirone, C. (1995). Shortterm memory in persons with intellectual disabilities and Down's syndrome. Journal of Intellectual Disability Research, 39, 532-537.

Wang, P.P. \& Bellugi, U. (1994). Evidence from two genetic syndromes for a dissociation between verbal and visuospatial short-term memory. Journal of Clinical and Experimental Neuropsychology, 16, 317-322.

Wishart, J.G. \& Johnston, F. H. (1990). The effects of experience on attribution of a stereotyped personality to children with Down's syndrome. Journal of Mental Deficiency Research, 34, 409-420. 